EESTI NSV TEADUSTE AKADEEMIA TOIMETISED. XVIII KÖIDE KEEMIA * GEOLOOGIA, 1969, NR. 3

ИЗВЕСТИЯ АКАДЕМИИ НАУК ЭСТОНСКОИ ССР. ТОМ XVIII ХИМИЯ * ГЕОЛОГИЯ. 1969, № 3

\author{
E. ГУСЬKOBA
}

\title{
МАГНИТНЫЕ СВОЙСТВА МЕТЕОРИТОВ КОЛЛЕКЦИИ ИНСТИТУТА ГЕОЛОГИИ АКАДЕМИИ НАУК ЭСТОНСКОЙ ССР
}

В Ленинградском отделении Института земного магнетизма, ионосферы и распространения радиоволн АН СССР в течение ряда лет ведутся исследования магнитных свойств метеоритов различных коллекций Советского Союза. В настоящее время исследовано более 700 образцов метеоритов из коллекций Ленинграда, Москвы, Қазани, Свердловска, Харькова, Одессы и Киева.

В мае 1967 года проводились исследования магнитных свойств метеоритов коллекции Института геологии АН ЭССР.

Обычно при исследованиях такого рода представляют интерес основные магнитные характеристики образцов метеоритов - естественная остаточная намагниченность $I_{n}$ и магнитная восприимчивость $x$. Естественная остаточная намагниченность $I_{n}$ представляет собой векторную сумму всех имеющихся в образце намагниченностей, возникающих в различное время и в различных условиях (температура, давление и т. д.). Магнитная восприимчивость $\varkappa$ характеризует способность образца метеорита намагничиваться в магнитном поле и зависит от содержания и типа ферромагнитных минералов.

Измерения магнитных свойств производились на астатическом магнитометре Долгинова, схема которого приведена на рис. 1. В немагнитном домике (1) на тонкой капроновой нити (2) подвешена астатическая магнитная система (3). Измеряемый образец метеорита помещается или на боковую шину прибора (положение I), или подносится снизу (положение II). Угол отклонения магнитной системы под действием магнитного момента образца метеорита фиксируется оптически с помощью зеркала (4). Цена деления магнитометра $\varepsilon$ зависит от расстояния $R$ образца метеорита от магнитной системы и может изменяться в пределах 1,5-4,5 $\gamma^{\prime}$ мм, где $\gamma$ - единица напряженности магнитного поля, равная $10^{-5}$ э. На рис. 2 изображены градуировочные кривые астатического магнитометра при различных расстояниях $R$ и различном положении системы магнитометра относительно магнитного поля Зем-

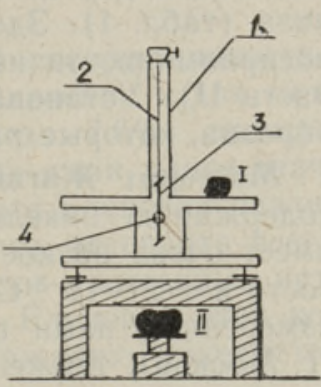

Рис. 1. ли: кривая I - астатическая система параллельна земному меридиану, кривая II - астатическая система перпендикулярна земному меридиану. Погрешность измерений естественной остаточной намагниченности $I_{n}$ 
достигает $5 \%$, магнитной восприимчивости $x-10 \%$ для всех типов метеоритов - каменных, железокаменных и железных.

В коллекции Института геологии АН ӘССР измерено 172 образца метеоритов, из них каменных - 107, железокаменных - 14, желез-

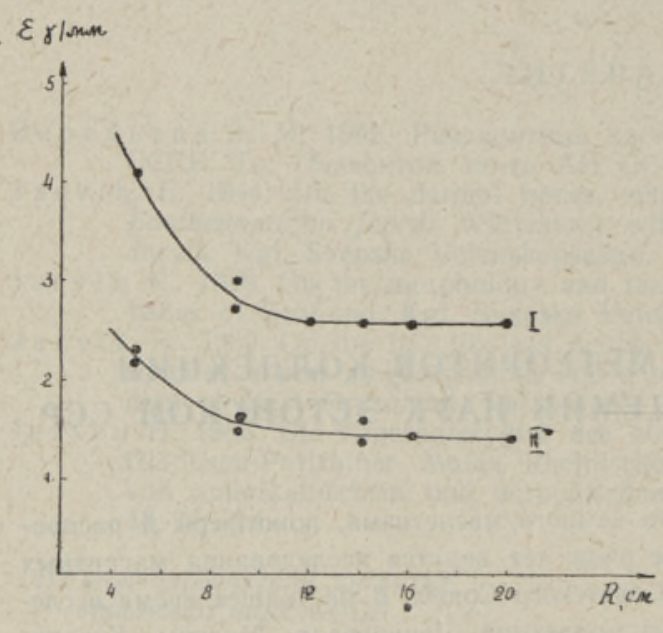

Рис. 2 ных - 51. Полученные данные сведены в табл. 1, где вместе с $I_{n}$ и $\approx$ приведены вес образца в граммах, содержание никелистого железа в каменных метеоритах и краткая характеристика образца метеорита по литературным данным ' (Аалоэ, Нестор, 1963; Кваша, 1962; Орвику, 1955, 1963). Значения магнитных свойств варьируют в широких пределах, но подчиняются определенным закономерностям.

На рис. 3 изображены вариационные кривые естественной остаточной намагниченности $I_{n}$ (рис. $3 a$ ) и магнитной восприимчивости $x$ (рис. $3 б)$.

Как видно, наибольшее число каменных метеоритов (76 образцов, т. е. $70 \%$ ) имеют значения $I_{n}$ в пределах $(0-10) \cdot 10^{-3}$ СГС; в распределении $I_{n}$ железокаменных метеоритов четкого максимума не наблюдается; для железных метеоритов наибольшее число образцов имеет значения $I_{n}$ в пределах $(10-30) \cdot 10^{-3}$ СГС.

В распределении $\varkappa$ наиболее четкий максимум для каменных метеоритов наблюдается в пределах $(0-20) \cdot 10^{-3}$ СГС для метеоритов группы $L$ (содержание никелистого железа $2-12 \%$ ), более расплывчатый - в шределах $(60-90) \cdot 10^{-3}$ СГС для метеоритов группы $H$ (содержание никелистого железа $12-24 \%$ ). Для железокаменных максимум по магнитной восприимчивости $x$ расположен в пределах $(200-500) \cdot 10^{-3}$ СГС, для железных - в пределах $(500-1500) \cdot 10^{-3}$ СГС.

На рис. 4 показана зависимость магнитной восприимчивости от содержания никелистого железа для 50 образцов каменных метеоритов коллекции, для которых в литературе имеются данные химического анализа (табл. 1). Здесь наиболее четко видно разделение по магнитной восприимчивости на группу $L$ (на рисунке область I) и группу $H$ (область II). Установленной закономерности не подчиняются лишь три образца, которые рассмотрим подробнее.

Метеорит Жигайловка № 011. Образец метеорита Жигайловка по содержанию никелистого железа $(17,5 \%)$ относится к группе $H$, но имеет очень низкое для этой группы значение магнитной восприимчивости $x=21 \cdot 10^{-3}$ СГС. Интересно, что образец метеорита Жигайловка́, измеренный нами в коллекции Қомитета по метеоритам АН СССР (г. Москва), также показывает низкое значение магнитной восприимчивости $-x=14 \cdot 10^{-3}$ СГС. В метеорите Жигайловка имеются редкие включения никелистого железа довольно больших размеров (5-7 мм в диаметре), т. е. никелистое железо не распределено равномерно по всему объему, а сосредоточено в отдельных включениях. Очевидно, это и является причиной уменьшения магнитной восприимчивости при общем большом содержании ферромагнетика. 
Метеорит Жовтневый Хутор № 012. Содержание никелистого железа в метеорите Жовтневый Хутор — 16,3\%, значение же магнитной восприимчивости для образца этой коллекции всего лишь $x=17 \cdot 10^{-3}$

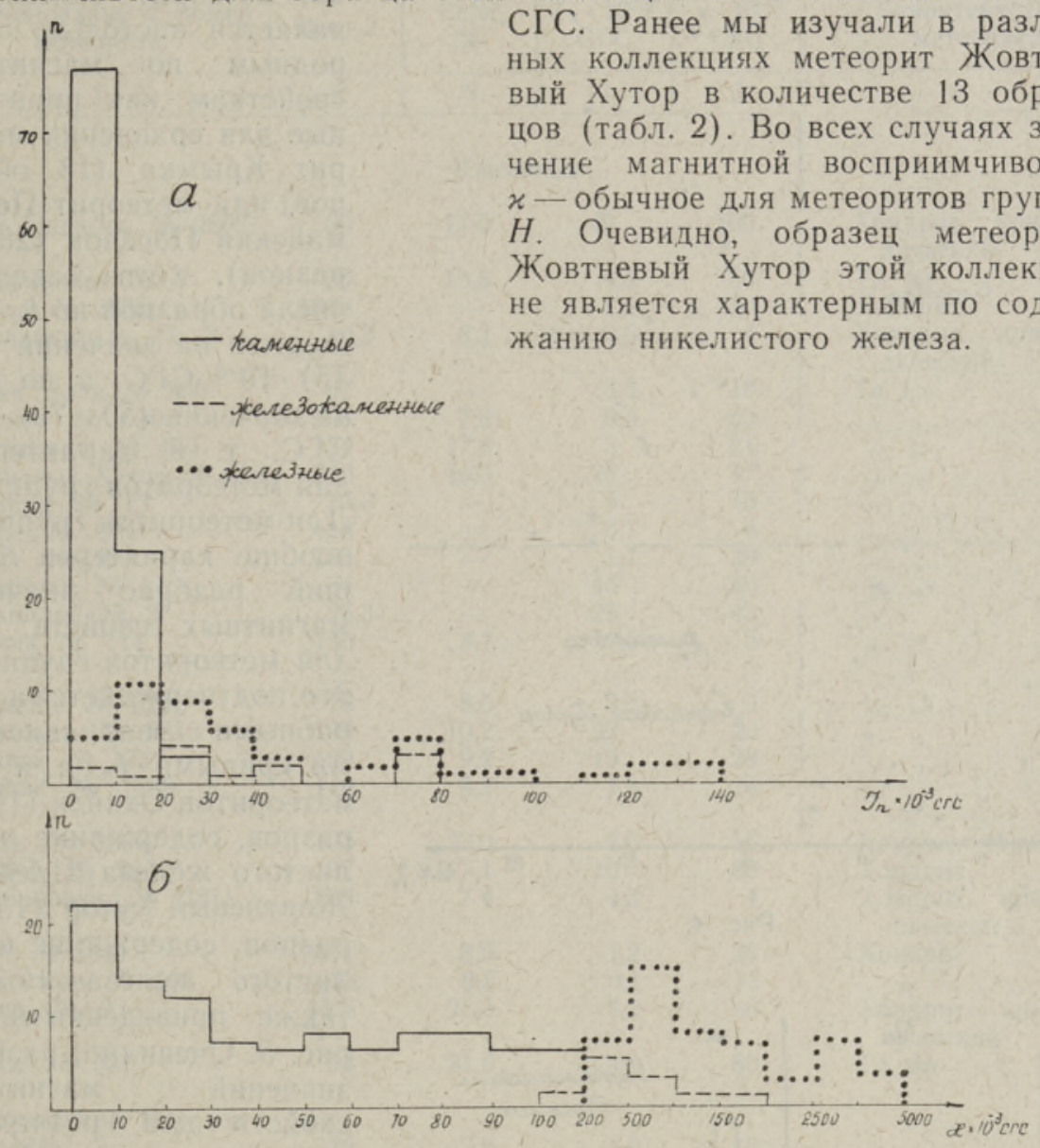

Рис. 3.

Метеорит Еленовка № 010. Значение магнитной восприимчивости у образца метеорита Еленовка превышает обычные значения $x$ для метеоритов группы $L$ (содержание никелистого железа $7,6 \%$, значение $x=63 \cdot 10^{-3}$ СГС). В табл. 2 приведены полученные нами ранее значения магнитных свойств для шести образцов метеорита Еленовка различных коллекций; как можно видеть, значения $x$ этого метеорита всегда соответствуют значениям магнитной восприимчивости $x$ каменных метеоритов группы $L$. Очевидно, и образец метеорита Еленовка этой коллекции также не является характерным по содержанию никелистого железа.

В коллекции метеоритов Академии наук Эстонской ССР подробно изучен метеорит Pultusk в количестве 37 образцов; кроме того, 24 образца метеорита Pultusk были ранее исследованы нами в различных коллекциях. Подробные вариационные кривые естественной остаточной намагниченности $I_{n}$ и магнитной восприимчивости $x$ для 61 образца 


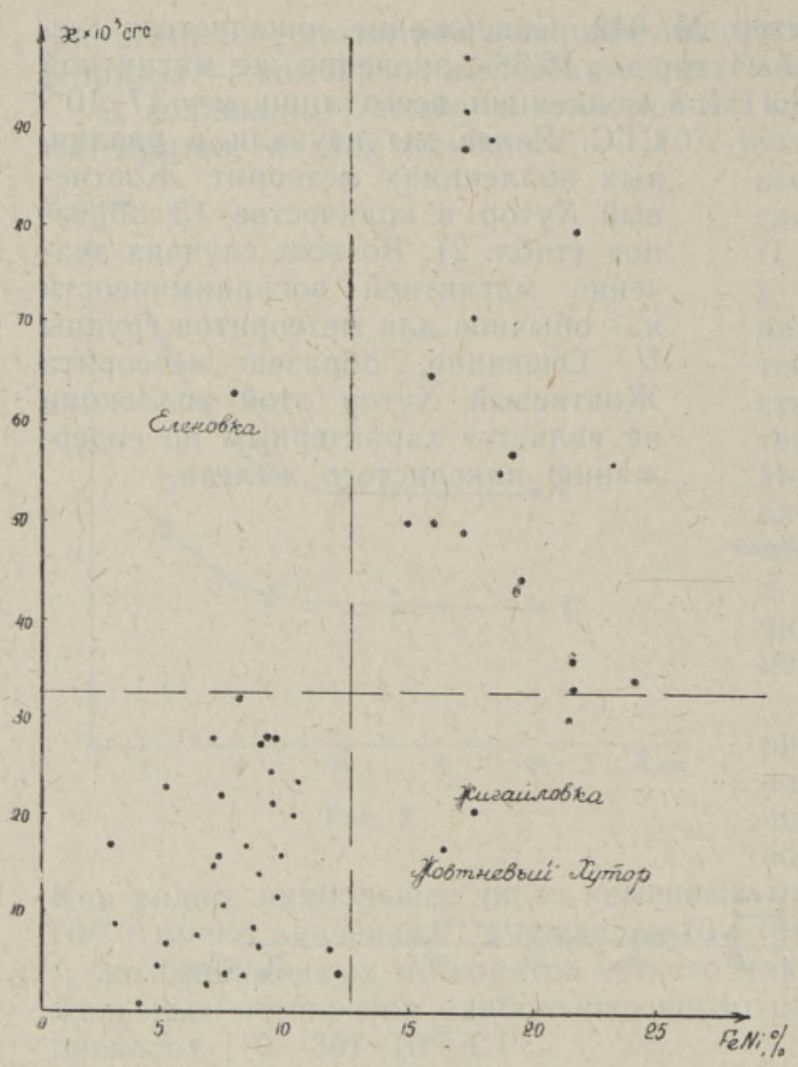

Puc. 4.
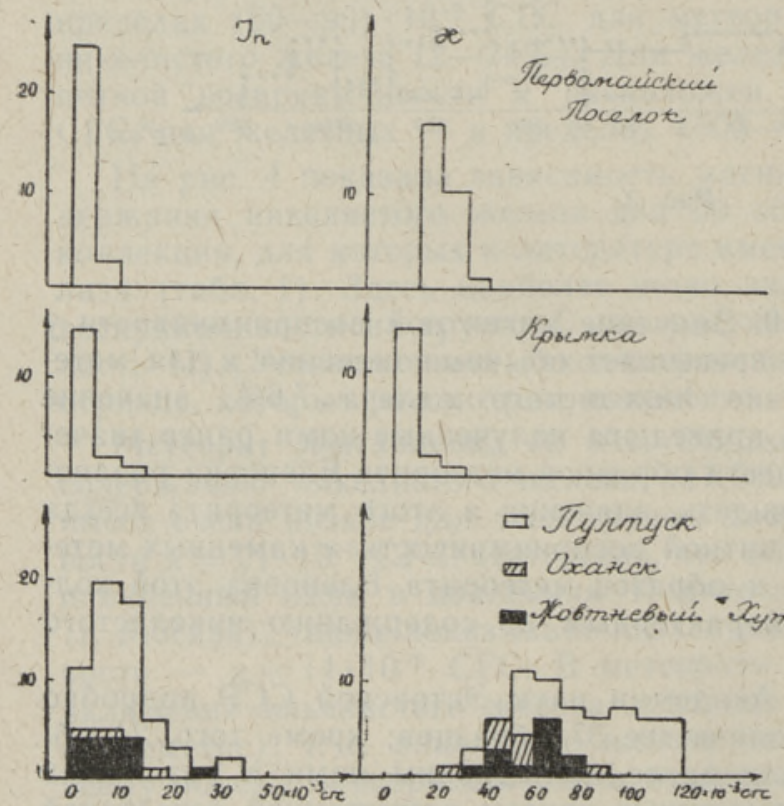

Рис. 5. метеорита Pultusk изображены на рис. 5. Как видно, метеорит Pultusk не является настолько однородным по магнитным свойствам, как приведенные для сравнения метеорит Крымка (18 образцов) или метеорит Первомайский Поселок (28 образцов), хотя максимум числа образцов по $I_{n}$ приходится на значения (515) $\cdot 10^{-3}$ СГС, а по $x-$ на значения $(50-70) \cdot 10^{-3}$ СГС, т. е. характерные для метеоритов группы $H$. Для метеоритов группы $H$ вообще характерен больший разброс значений магнитных свойств, чем для метеоритов группы $L$. Это подтверждается и подробными вариационными кривыми $I_{n}$ и $x$ для метеоритов Оханск (14 образцов, содержание никелистого железа $21,5 \%$ ) и Жовтневый Хутор (13 образцов, содержание никелистого железа 16,3\%), также приведенными на рис. 5. Очевидно, разброс значений магнитных свойств для различных образцов одного метеорита группы $H$ связан с неоднородным распределением никелистого железа то всему объему метеорита.

Среди исследованных метеоритов обращают на себя внимание два образца.

Образец среднеструктурного октаэдрита Carthage (№ 064, вес. 141 2; в табл. 1 не включен) показывает аномально высокое значение магнитной восприимчивости $x=$ $=25000 \cdot 10^{-3}$ СГС (в ленинградской коллекции 
Таблица 1

Магнитные свойства образцов метеоритов коллекции Институга геологии АН ЭССР

\begin{tabular}{c|c|c|c|c|c}
\hline $\begin{array}{c}\text { Наименование и номер } \\
\text { метеорита }\end{array}$ & Bec, 2 & $\begin{array}{c}\text { FeNi, } \\
\%\end{array}$ & $\begin{array}{c}I_{n} \cdot 10^{-3} \\
\text { СГC }\end{array}$ & $\begin{array}{c}x \cdot 10^{-3} \\
\text { СГC }\end{array}$ & $\begin{array}{c}\text { Характеристика } \\
\text { метеорита }\end{array}$ \\
\hline 1 & 2 & 3 & 4 & 5 & 6 \\
\hline
\end{tabular}

\section{Каменные}

Белая Церковь № 2803

Белокриничье № 2

Гросслибенталь № 7

Долгая Воля № 800

Еленовка № 010

Жигайловка № 011

Жовтневый Хутор № 012

Заборица № 13

Каанде № 014

Каанде № 014

Каргаполье № 1

Каргаполье № 2

Қнягиня № 114

Кузнецово № 229

Кулешовка № 2813

Кунашак № 1727

Кунашак № 1739

Ликсна № 2808

Миссхоф № 2847

Мордвиновка № 2811

Нерфт № 2844

Никольское № 191

Оханск № 23

Оханск № 597

Первомайский Поселок № 192

Пилиствере № 025c

Раковка № 2847

Саратов № 340

Севрюково № 29

Тимохина № 33

Тяннасильма № 2993

Alessandria № 043

Auson No 045

Bluff № 54

Bremervörde № 057

Butsura № 2837

Castalia № 065

Cereseto № 067

Chantonnay № 068

$\begin{array}{rccr}90 & 17,0 & 49 & 100 \\ 30 & 15,8 & 4,2 & 50 \\ 1014 & - & 1,4 & 10 \\ 10,2 & 8,2 & 0,5 & 4 \\ 67 & - & 3,5 & 10 \\ 905 & 7,6 & 0,5 & 63 \\ 34 & 17,5 & 3 & 21 \\ 330 & 16,3 & 22 & 17 \\ 19,3 & - & 5 & 15 \\ 458 & - & 6,7 & 8 \\ 758 & - & 1,7 & 29 \\ 34 & - & 45 & 60 \\ 26,3 & - & 28 & 43 \\ 150 & 4,7 & 1,0 & 5 \\ & & & \end{array}$

$\begin{array}{ll}76 & 8,6\end{array}$

$139-10,2$

$109 \quad 9,2$

$118 \quad 9,2$

$103 \quad 23,0$

$97 \quad 17,1$

$889 \quad 7,4$

3301

23

11,6

\section{8,9}

9,5
21,5

53.

21,5

29

158

276

227

7,0

24,0

7,2

9,4

$\begin{array}{ll}194 & 9,7\end{array}$

44,8

18

2747

31

10,4

10

152

12

28

98

-

8,9

29

37
2,2
22

19

1,6

\section{4,5}

10

4,5

1,2
0,1

0,1

4

7,3

\section{1,0
5,3}

5,3

3,5

19

16

89

23

40

7,0

3

4

22

$$
3,5
$$

28

9
20

28

24

56

88
4

28

12
36

80

15

33

21

16

89

23

2

$20 \quad 28$

$\begin{array}{ll}1,8 & 13\end{array}$

$6 \quad 60$

6,7

0,1
Хондрит кристаллический

То же

Хондрит

Хондрит кристаллический

То же

, "

, "

,$\quad$,

, "

,,

,$\quad$,

, "

,$\quad$,

$$
\begin{aligned}
& ", \quad \\
& ", \\
& ", \\
& " \quad "
\end{aligned}
$$

Хондрит темный

Хондрит

Хондрит кристаллический

Хондрит

Хондрит кристаллический

То же

$"$,

" ,

Хондири ненный

То же

Хондрит кристаллический

Хондрит

Хондрит жилковатый, серый

Хондрит шариковый

Хондрит кристаллический

Хондрит шариковый

Хондрит промежуточный

Хондрит брекчиевый

Хондрит шариковый

Хондрит серый 


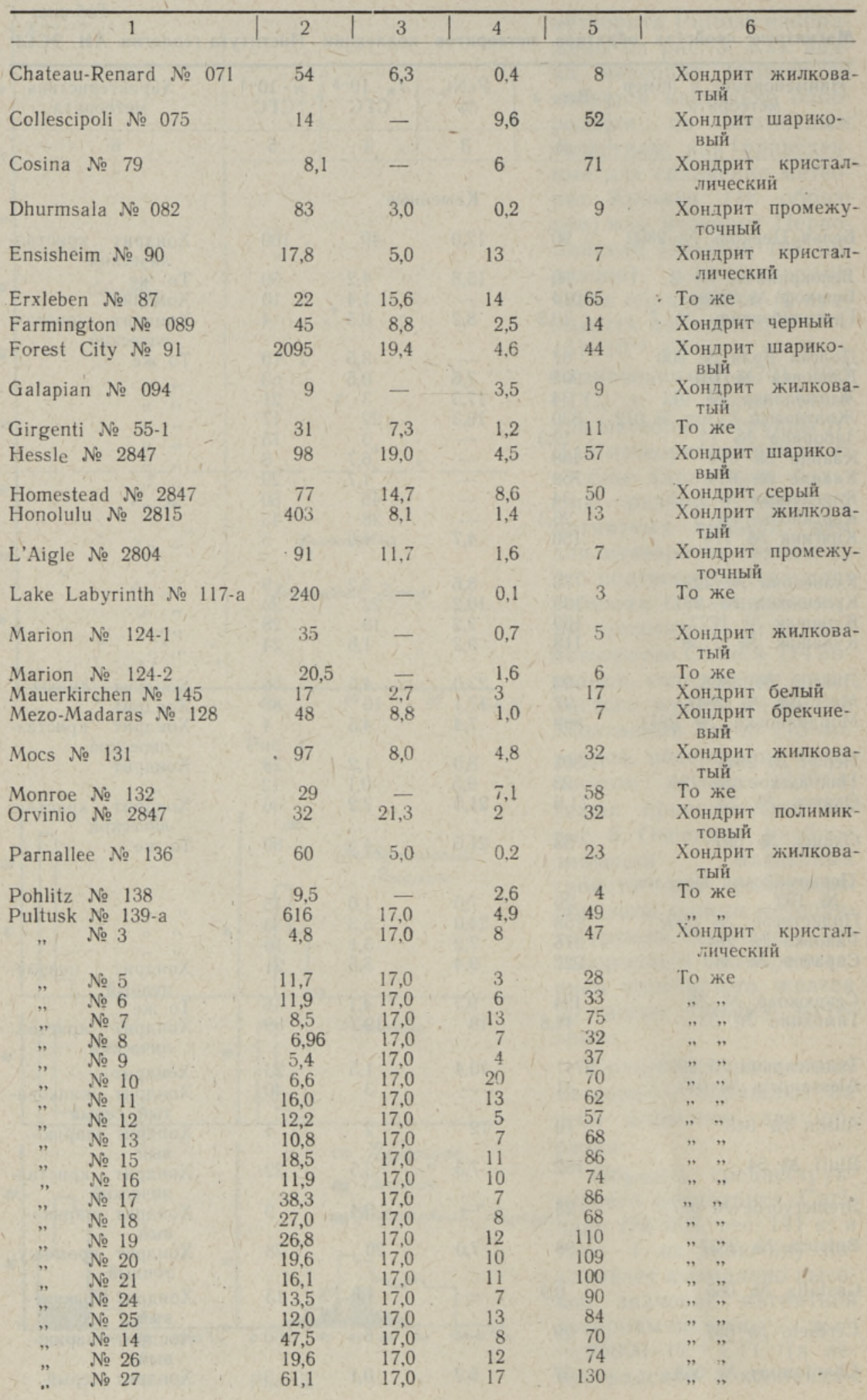




\begin{tabular}{|c|c|c|c|c|c|c|}
\hline 1 & 2 & 3 & 4 & 5 & 6 & \\
\hline Pultusk № 28 & 15,3 & 17,0 & 7 & 77 & $\begin{array}{l}\text { Хондрит } \\
\text { лически }\end{array}$ & ирй \\
\hline , $\quad$ № 29 & 13,0 & 17,0 & 10 & 90 & Tо же & \\
\hline " & 12,8 & 17,0 & 11 & 110 & , " & \\
\hline " & 28,5 & 17,0 & 15 & 87 & $" n$ & \\
\hline , № 35 & 26,1 & 17,0 & 6 & 78 & $", "$ & \\
\hline " № 36 & 14,6 & 17,0 & 13 & 118 & $" \quad "$ & \\
\hline " $\quad$ № 49 & 25,3 & 17,0 & 12 & 107 & $" \quad "$ & \\
\hline " $\quad$ № 50 & 18,9 & 17,0 & 18 & 125 & $"$, & \\
\hline " № 51 & 12,2 & 17,0 & 11 & 80 & , & \\
\hline " № 53 & 22,0 & 17,0 & 16 & 114 & $" \quad$, & \\
\hline " № 54 & 16,3 & 17,0 & 6 & 96 & $"$, & \\
\hline № 56 & 51,7 & 17,0 & 10 & 140 & $" \quad "$ & \\
\hline , № 58 & 16,2 & 17,0 & 11 & 100 & 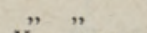 & \\
\hline , № 57 & 242 & 17,0 & 18 & 92 & $\begin{array}{l}\text { Хондрит } \\
\text { тый }\end{array}$ & жилкова- \\
\hline Renazzo № 103 & 6,7 & 一 & 4 & 10 & Хондрит & черный \\
\hline Soco-Banja № 156 & 155 & 4,0 & 0,5 & 1,0 & $\begin{array}{l}\text { Хондрит } \\
\text { вый }\end{array}$ & шарнко- \\
\hline Trenzano № 127 & 206 & 18,5 & 14 & 55 & $\begin{array}{l}\text { Хондрит } \\
\text { тый }\end{array}$ & жилкова- \\
\hline Vouillé № 171 & 16 & 8,3 & 0,7 & 17 & $\begin{array}{l}\text { Tо же } \\
\text { Хондрит }\end{array}$ & шарико- \\
\hline Waconda № 132 & 463 & 9,1 & 2,8 & 28 & вый & \\
\hline Wold Cottage № 136 & 14,9 & - & 2,6 & 15 & $\begin{array}{l}\text { Хондрит } \\
\text { тый }\end{array}$ & жилікова- \\
\hline
\end{tabular}

\begin{tabular}{c|c|c|c|c}
\hline $\begin{array}{c}\text { Наименование и номер } \\
\text { метеорита }\end{array}$ & Вес, 2 & $I_{n} \cdot 10^{-3}$ СГC & $\begin{array}{c}x \cdot 10^{-3} \\
\text { СГC }\end{array}$ & $\begin{array}{c}\text { Характеристика } \\
\text { метеорита }\end{array}$ \\
\hline 1 & 2 & 3 & 4 & 5 \\
\hline
\end{tabular}

$\begin{array}{ll}\text { Брагин № } 004 & 157 \\ \text { Dona Inez № } 180 & 19,2 \\ \text { Estherville № } 880 & 10,9 \\ \text { Imilac № 2852 } & 68 \\ \text { Inca № 181 } & 17 \\ \text { Crab Orchard № } 080 & 88 \\ \text { Нечаево № 020 } & 44 \\ \text { Нечаево № 20 } & 73 \\ \text { Палласово Железо № 024 } & 38 \\ \text { Палласово Железо } & \\ \text { № 2848-1 } & 128 \\ \text { Палласово Железо } & \\ \text { № 2848-2 } & 104 \\ \text { Steinbach № 160 } & 80 \\ \text { Наinholz № 2832 } & 13,6 \\ \text { Ямышева № 2848 } & 49\end{array}$

\section{Atacama}

Butler № 59

Bella Roca № 47

Bendego № 048

Bethany № 049

Blick Mountain № 53

Boxhole № 55
128

104

13,6

49

30

41

19

52
Железокаменные

$157 \quad 28$

$19,2 \quad 24$

$\begin{array}{ll}10,9 & 25\end{array}$

$68 \quad 45$

$17-12$

$\begin{array}{ll}88 & 73\end{array}$

$8 \quad 210$

81

250

$12 \quad 60$

$73 \quad 800$

$9 \quad 1850$

$9 \quad 600$

$\begin{array}{ll}77 & 1250\end{array}$

77

35

150

41

130

$350^{\circ}$

250

150

1100

Железные

$71 \quad 800$

$120 \quad 22$

$\begin{array}{ll}73 & 720\end{array}$

$14 \quad 1180$

$33 \quad 1350$

12

470

136
Палласит

Мезосидери г

Палласит

Мезосидерит

Грахамит

Палл̈асит

Сидерофир

мезосидерит

Палласит

Октаэдрит среднеструктурный

Октаэдрит очень тонкострукт урный

Октаэдрит тонкоструктурный

Октаэдрит грубоструктурный

Октаэдрит тонкоструктурный

Октаэдрит грубоструктурный

Октаэдрит среднеструктурный 


\begin{tabular}{|c|c|c|c|c|}
\hline 1 & 2 & 3 & 4 & 5 \\
\hline 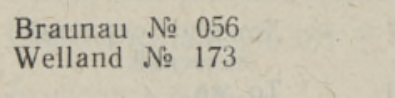 & $\begin{array}{r}15 \\
515\end{array}$ & $\begin{array}{l}11 \\
24\end{array}$ & $\begin{array}{l}710 \\
900\end{array}$ & $\begin{array}{l}\text { Гексаэдрит } \\
\text { Октаэдрит средне- } \\
\text { структурный }\end{array}$ \\
\hline Wichita County № 175 & 398 & 9 & 1200 & $\begin{array}{l}\text { Октаэдрит груб́о- } \\
\text { структурный }\end{array}$ \\
\hline $\begin{array}{l}\text { Гресск № } 188 \\
\text { Denton County № } 081\end{array}$ & $\begin{array}{r}705 \\
45\end{array}$ & $\begin{array}{l}30 \\
49\end{array}$ & $\begin{array}{l}1200 \\
6400\end{array}$ & $\begin{array}{l}\text { Гексаэдрит } \\
\text { Октаэдрит средне- } \\
\text { структурный }\end{array}$ \\
\hline Duel Hill № 084 & 17 & 128 & 510 & $\begin{array}{l}\text { Октаэдрит гру5о- } \\
\text { структурный }\end{array}$ \\
\hline Elbogen № 085 & 7,6 & 22 & 1100 & $\begin{array}{l}\text { Октаэдрит средне- } \\
\text { структурный }\end{array}$ \\
\hline Cañon Diablo № 1874 & 166 & 48 & 120 & $\begin{array}{l}\text { Октаэдрит грубо- } \\
\text { структурный }\end{array}$ \\
\hline $\begin{array}{l}\text { Coahuila } \text { № } 73 \\
\text { Coahuila } \\
\text { № } 073\end{array}$ & $\begin{array}{l}109 \\
290\end{array}$ & $\begin{array}{l}91 \\
19\end{array}$ & $\begin{array}{l}2700 \\
1400\end{array}$ & \\
\hline Coolac № 76 & 149 & 27 & 1800 & $\begin{array}{l}\text { Октаэдрит грубо- } \\
\text { структурный }\end{array}$ \\
\hline Coopertown № 81 & 30,2 & 62 & 1300 & $\begin{array}{l}\text { Окта̇эдрит средне- } \\
\text { структурный }\end{array}$ \\
\hline $\begin{array}{l}\text { Kendall C. № } 110 \\
\text { Kenton C. № } 111\end{array}$ & $\begin{array}{r}197 \\
83\end{array}$ & $\begin{array}{r}265 \\
71\end{array}$ & $\begin{array}{r}375 \\
2800\end{array}$ & $\begin{array}{l}\text { Гексаэдрит } \\
\text { Октаэдрит средне- } \\
\text { структурный }\end{array}$ \\
\hline $\begin{array}{l}\text { La Caille № } 115 \\
\text { Lenarto № } 78 \\
\text { Madoc № } 122\end{array}$ & $\begin{array}{l}50 \\
51,9 \\
28\end{array}$ & $\begin{array}{r}12 \\
2 \\
37\end{array}$ & $\begin{array}{r}1350 \\
880 \\
460\end{array}$ & $\begin{array}{l}\text { То же } \\
\text { Октаздрит тонко- } \\
\text { структурный }\end{array}$ \\
\hline Merceditas № 127 & 881 & 46 & 1330 & $\begin{array}{l}\text { Октаэдрит средне- } \\
\text { структурный }\end{array}$ \\
\hline Ниро № 021 & 115 & 18 & 2300 & $\begin{array}{l}\text { Октаэдрит грубо- } \\
\text { структурный }\end{array}$ \\
\hline Puquios № 140 & 219 & 79 & 2000 & $\begin{array}{l}\text { Октаэдрит средне- } \\
\text { структурный }\end{array}$ \\
\hline Putnam C. № 141 & 28 & 13 & 350 & $\begin{array}{l}\text { Октаэдрит тонко- } \\
\text { структурный }\end{array}$ \\
\hline $\begin{array}{l}\text { Russel Gulch № } 146 \\
\text { Salt River № } 2863\end{array}$ & $\begin{array}{l}85 \\
81\end{array}$ & $\begin{array}{r}75 \\
210\end{array}$ & $\begin{array}{r}200 \\
3150\end{array}$ & То же \\
\hline $\begin{array}{l}\text { Santa Catharina № } 148 \\
\text { Scriba № } 185\end{array}$ & & & $\begin{array}{r}2900 \\
810\end{array}$ & $\begin{array}{l}\text { Ӓтаксит богатый } \\
\text { Октаэдрит грубо- }\end{array}$ \\
\hline $\begin{array}{c}\text { Capenta № } 28 \\
\text { Seeläsgen № } 150 \\
"=\quad № 150\end{array}$ & $\begin{array}{r}41 \\
104 \\
13\end{array}$ & $\begin{array}{l}17 \\
28 \\
35 \\
\end{array}$ & $\begin{array}{l}3000 \\
1000 \\
2100\end{array}$ & $\begin{array}{l}\text { структурный } \\
\text { То же } \\
\text { Октаэдрит очень } \\
\text { грубоструктурный }\end{array}$ \\
\hline Seneca Falls № 152 & 50 & 4 & 0 & $\begin{array}{l}\text { Октаэдрит средне- } \\
\text { структурный }\end{array}$ \\
\hline Sierra Blanca № 154 & 228 & 12 & 800 & $\begin{array}{l}\text { Октаэдрит грубо- } \\
\text { структурный }\end{array}$ \\
\hline $\begin{array}{l}\text { Сихотэ-Алинь № } 30 \\
\text { Tazewell № } 163\end{array}$ & $\begin{array}{r}2474 \\
56\end{array}$ & $\begin{array}{l}22 \\
82\end{array}$ & $\begin{array}{r}1200 \\
1800\end{array}$ & $\begin{array}{l}\text { То же } \\
\text { Октаэдрит тонко- } \\
\text { структурный }\end{array}$ \\
\hline Toluca № 165 & 73 & 36 & 750 & $\begin{array}{l}\text { Октаэлрит средне- } \\
\text { структурный }\end{array}$ \\
\hline $\begin{array}{l}\text { „№ } 125 \\
\text { Tucson № } 168 \\
\text { Fort Pierre № } 093\end{array}$ & $\begin{array}{r}1230 \\
12,5 \\
10,6\end{array}$ & $\begin{array}{l}29 \\
16 \\
63\end{array}$ & $\begin{array}{l}660 \\
290 \\
560\end{array}$ & $\begin{array}{l}\text { To же } \\
\text { Атаксит бедный } \\
\text { Октаэдрит средне- } \\
\text { структурный }\end{array}$ \\
\hline Henbury № 100 & $\begin{array}{r}30 \\
2209\end{array}$ & $\begin{array}{r}4 \\
26\end{array}$ & $\begin{array}{r}500 \\
370\end{array}$ & "T \\
\hline $\begin{array}{l}\text { Hex River Mountain № } 102 \\
\text { Zacatecas № } 178\end{array}$ & $\begin{array}{r}337 \\
27\end{array}$ & $\begin{array}{l}31 \\
28\end{array}$ & $\begin{array}{r}1950 \\
630\end{array}$ & $\begin{array}{l}\text { Гексаэдрит } \\
\text { Октаэдрит брек- }\end{array}$ \\
\hline Чебанкол № 194 & 162 & 135 & 4000 & $\begin{array}{l}\text { Октаэдрит грубо- } \\
\text { структурный }\end{array}$ \\
\hline $\begin{array}{l}\text { Chesterville № } 72 \\
\text { Чннге № } 195 \\
\text { Schwetz № } 2862\end{array}$ & $\begin{array}{r}44 \\
96 \\
162\end{array}$ & $\begin{array}{r}15 \\
125 \\
36\end{array}$ & $\begin{array}{r}1450 \\
1880 \\
860\end{array}$ & $\begin{array}{l}\text { Атаксит бедный } \\
\text { богатый } \\
\text { Октаэдрит средне- } \\
\text { структурный }\end{array}$ \\
\hline
\end{tabular}


образец метеорита Carthage имеет значение $x=1600 \cdot 10^{-3}$ СГС). Таких высоких значений $x$ не наблюдалось ни у одного из исследованных нами 280 образцов железных метеоритов. Возможно, увеличение магнитной восприимчивости связано с сильным нагреванием образца мегеорита Carthage в особых условиях, о чем может свидетельствовать побежалость синего цвета на поверхности образца этого метеорита.

У образца среднеструктурного октаэдрита Seneca Falls (№ 152, вес 50 г) наблюдается аномально низкое значение магнитной восприимчивости - $x \sim 0$; в других коллекциях образцов этого метеорита мы не встречали. Следует предположить, что данный образец каким-то образом подвергся размагничиванию и потерял магнитные свойства, присущие всем железным метеоритам.

Таким образом, проведенные исследования магнитных свойств метеоритов коллекции Академии наук Эстонской ССР позволяют сделать следующие выводы:

1. Все метеориты обладают магнитными свойствами; наблюдается постепенное увеличение магнитных свойств от каменных к железным метеоритам, что связано с увеличением содержания никелистого железа - основного ферромагнетика метеоритов всех типов.

2. Аномальные по магнитным свойствам образцы встречаются довольно редко, отклонение магнитных свойств от установленных значений почти всегда может быть объяснено индивидуальными особенностями образца.

3. Магннтная восприимчивость каменных метеоритов $x$ находится в прямой зависимости от содержания никелистого железа; не более $5 \%$ образцов показывают отклонения от этой зависимости, и по значению $x$ четко определяется принадлежность метеорита к группе $L$ или $H$.

4. Метеориты группы $L$ более однородны по магнитным свойствам, чем метеориты группы $H$.

Подобные исследования проведены впервые и имеют большое значение для познания природы метеоритов, так как магнитные свойства одна из важнейших физических характеристик вещества. Проведенные ранее исследования большого количества образцов метеоритов в лаборатории позволили сделать предположение, что магнитные свойства их имеют внеземное происхождение и могли быть приобретены метеоритами во время образования их в межпланетном пространстве. Эти данные следует учитывать при построении любой схемы происхождения метеоритов всех типов. 
Л И Т Р А Т Р А

А алоэ А. О., Нестор Х. Э. 1963. Метеориты коллекции Института геологин Академии наук ЭССР. Тр. Ин-та геол., 11.

К в аша Л. Г. 1962. Каталог метеоритов коллекции Комитета по метеоритам Академии наук СССР на 1 июля 1961 года. Метеоритика, вып. 12.

О р в и ку К. К. 1955. Метєорнты коллекции Геологического института Академии наук Эстонской ССР (г. Тарту). Метеоритика, вып. 12.

О р в и к у К. К. 1963. Коллекция метеоритов Академии наук Эстонской ССР. Тр. Ин-та геол. АН ЭССР, 11.

Институт земного магнетизма, ионосферы

и риспрострснения радиоволн АН СССР,

Поступила в редакцию

Ленинградское отделение

23/VII 1968

\section{J. GUSKOVA}

\section{EESTI NSV TEADUSTE AKADEEMIA GEOLOOGIA INSTITUUDI KOLLEKTSIOONIS OLEVATE METEORIITIDE MAGNETILISED OMADUSED}

Esitatakse ENSV TA Geoloogia Instituudi kollektsioonis olevate meteoriitide magnetiliste omaduste - loodusliku jääkmagnetismi $I_{n}$ ja magnetilise sustseptiibluse $x$ uurimise tulemused.

Kokku uuriti 172 meteoriiti, neist 107 kivi-, 14 sega- ja 51 raudmeteoriiti.

Selgus, et kõik meteoriidid on magnetilised. On tăheldatav pidev magnetiliste omaduste tugevdamine kivimeteoriitidest raudmeteoriitide suunas, sõltuvalt nikkelraua sisalduse suurenemisest. Anomaalsete omadustega eksemplare leidub harva, kusjuures, kōrvalekaldumised on peaaegu alati seletatavad meteoriidi individuaalse omapäraga. Nikkelrauasisaldusest otseselt sổltuv on kivimeteoriitide magnetiline sustseptiiblus. Kỗrvalekaldumisi sellest sõltuvusest ei esine üle $5 \%$ eksemplaridel ning $*$ väärtuse järgi on selgelt piiritleta々 meteoriidi kuuluvus $L$ või $H$ gruppi.

\section{J. GUSKOVA}

\section{DIE MAGNETISCHEN EIGENSCHAFTEN DER METEORITE AUS DER KOLLEKTION DES INSTITUTS FUR GEOLOGIE DER AKADEMIE DER WISSENSCHAFTEN DER ESTNISCHEN SSR}

In 1967 wurden die Meteorite aus der Kollektion des Instituts für Geologie der Akademie der Wissenschaften der Estnischen SSR auf ihre magnetischen Eigenschaften die natürliche remanente Magnetisierung $I_{n}$ und die magnetische Suszeptibilität $x-$ geprüft. Die Messungen erfolgten mit Hilfe eines astatischen Magnitometers von Dolginov (Wert der Teilung $\varepsilon=1,5-4,5 \gamma \mathrm{mm}$ ) (Abb. 1 und 2); möglicher Fehler der Messungen für $I_{n}-5 \%$, für $x-10 \%$.

Die erzielten Resultate für 172 Meteorite (107 Steinmeteorite, 14 Mesosiderite, 51 Eisenmeteorite) werden in Tab. 1 dargestellt, wo außerdem das Gewicht des Meteorits in g, sein Gehalt an Nickeleisen und seine kurze Charakteristik laut vorhandenen Literatura,ngaben gebracht wird.

Die Variationskurven der natürlichen remanenten Magnetisierung $I_{n}$ und der magnetischen Suszeptibilität $\varkappa$ bezeugen (Abb. 3), da $\mathbf{B}$ die meisten Steinmeteorite $(70 \%)$ den Wort von $I_{n}$ in den Grenzen von $(0-10) \cdot 10^{-3}$ CGS liegen haben. Bei den Mesosideriten weist die Verteilung des Werts von $I_{n}$ kein deutliches Maximum auf. Bei den meisten Eisenmeteoriten liegt $I_{n}$ in den Grenzen von $(10-30) \cdot 10^{-3}$ CGS.

In der Verteilung von $x$ kann das deutlichste Maximum bei Steinmeteoriten innerhalb von $(0-20) \cdot 10^{-3}$ CGS beobachtet werden - nämlich für Meteorite der Gruppe L. Bei Mesosideriten liegt das Maximum der magnetischen Suszeptibilität $x$ in den Grenzen von $(200-500) \cdot 10^{-3}$ CGS, bei Eisenmeteoriten in den Grenzen von $(500-1500) \cdot 10^{-3}$ CGS

An Hand von 50 Steinmeteoriten, deren chemische Zusammensetzung in der Literatur angegeben worden ist, wird auf $\mathrm{Abb}$. 4 die Abhängigkeit der magnetischen Suszeptibilität $\approx$ vom Nickeleisengehalt dargestellt. Hier kommt die Teilung der magnetischen Suszeptibilität $x$ in Gruppe L (Gebiet 1) und Gruppe H (Gebiet 2) am deutlichsten zum Vorschein. 
Aus den dargebrachten Variationskurven der Werte $I_{n}$ und $x$ für die Meteorite Pultusk, Krymka, Pervomaisky Posiolok, Ochansk und Zhowtnevyi Khutor ist ersichtlich, daB die Meteorite der Gruppe $\mathrm{H}$ ihren magnetischen Eigenschaften nach weniger einheitlich sind als die Meteorite der Gruppe L; dieses ist augenscheinlich durch die ungleichmäßige Verteilung des Nickeleisens über den ganzen Meteorit zu erklären.

Die besprochene Untersuchung der magnetischen Eigenschaften der Meteorite aus der Kollektion der Akademie der Wissenschaften der Estnischen SSR erlaubt es, folgende Schlüsse zu ziehen:

1) sämtliche Meteorite weisen magnetische Eigenschaften auf. Diese Eigenschaften wachsen von den Steinmeteoriten zu den Eisenmeteoriten nach und nach an, was mit der Vergrößerung des Gehalts an Nickeleisen, dem wesentlichen eisenmagnetischen Bestandteil aller Typen, verbunden ist;

2) Anomalien der magnetischen Eigenschaften kommen bei den Meteoriten ziemlich selten vor; die Abweichungen der magnetischen Eigenschaften von den festgestellten Größen können fast immer durch individuelle Eigentümlichkeiten des gegebenen Exemplars erklärt werden;

3) die magnetische Suszeptibilität $I_{n}$ der Steinmeteorite ist vom Nickeleisengehalt direkt abhängig. Abweichungen von dieser Abhängigkeit kommen bei höchstens $5 \%$ der Exemplare vor; die Größe von $\varkappa$ bestimmt deutlich die Zugehörigkeit des Meteorits zur Gruppe $\mathrm{L}$ oder $\mathrm{H}$.

Derartige Untersuchungen sind erstmalig; sie sind für die Kenntnis der Natur der Meteorite von großer Wichtigkeit, da die magnetischen Eigenschaften zu den wesentlichsten Charakteristiken des Stoffes gehören. Frühere Untersuchungen einer großen Anzahl von Meteoriten im Labor erlauben die Annahme, daß die magnetischen Eigenschaften der Meteorite außerirdischer Herkunft sind und bei ihrer Entstehung im interplanetaren Raum erlangt worden sind. 